\title{
ПОРІВНЯЛЬНА ЕФЕКТИВНІСТЬ КЛАСИФІКАТОРІВ ЗОБРАЖЕНЬ ПІД ЧАС РОЗПІЗНАВАННЯ ЗОН ІНТЕРЕСУ ПРИ ЛАПАРОСКОПІЧНИХ ВТРУЧАННЯХ
}

\author{
М. Р. Баязітов, Д. М. Баязітов, А. Б. Бузиновський, \\ А. В. Ляшенко, Д. В. Новіков, Л. С. Годлевський \\ Одеський національний медичний університет
}

\begin{abstract}
У роботі представлено порівняльне оцінювання ефективності систем автоматизованої комп'ютерної діагностики, розроблених на основі двох класифрікаторів - каскаду дескрипторів Хаapa та AdaBoost, під час лапароскопічної діагностики апендициту та метастазів печінки.

Для навчання використовували зображення, а також гама-кореговані та конвертовані у HSV шкалу кольори RGB зображення, отримані під час лапароскопічної діагностики. Дескриптори, що використовували для навчання класифрікатора AdaBoost отримували за допомогою методу локального бінарного патерну, який включав інформаційні показники кольору, а також показники текстури. Після завершення навчання проводили тест оцінювання есрективності діагностики при якому використовували зображення, що не застосовували для навчання.

Найбільш високим показник повноти (recall) був при тестовій діагностиці апендициту за допомогою навчання класифрікатора AdaBoost дескрипторами модифікованого кольору локального бінарного патерну, отриманими 3 RGB зображень, - 0,745, а під час діагностики метастазів печінки - 0,902. Також коректність діагностики (ассигасу) склала 74,4 \% під час діагностики апендициту та 89,3% при діагностиці метастазів печінки. Коректність діагностики із застосуванням класифрікатора Хаара була найбільш високою за умови діагностики метастазів печінки та склала 0,672 при використанні RGB зображень, 0,723 - при навчанні HSV зображеннями.

Діагностика із застосуванням класифрікатора Хаара $€$ менш ефективною порівняно з діагностикою, що здійснювалась із застосуванням класифрікатора AdaBoost, навчання якого здійснювали із застосуванням дескрипторів модифрікованого кольору локального бінарного патерну.
\end{abstract}

Ключові слова: аналіз зображень, машинне навчання, дескриптори Хаaра, класифікатор AdaBoost, лапароскопічна хірургія.

\section{THE COMPARATIVE EFFECTIVENESS OF IMAGES CLASSIFIERS IN THE COURSE OF RECOGNITION OF ZONES OF INTEREST DURING LAPAROSCOPIC INTERVENTION}

\author{
N. R. Bayazitov, D. N. Bayazitov, A. B. Buzynovsky, \\ A. V. Lyashenko, D. V. Novikov, L. S. Godlevsky \\ Odessa National Medical University
}

\begin{abstract}
Background. The purpose of the study is to evaluate the effectiveness of the automatic computer diagnostic (ACD) systems developed on the basis of two classifiers - HAAR features cascade and AdaBoost for the detection of appendicitis and metastatic damages of the liver.

Materials and methods. For the classifiers training the images/frames, which have been cropped out from video gained in the course of laparoscopic diagnostics were used. Namely, RGB frames, and gamma-corrected RGB frames and converted into HSV have been explored. Also descriptors were extracted from images with the modified method of Local Binary Pattern (LBT), which includes data on color characteristics («modified color LBT» — MCLBT) and textural ones were used later on for AdaBoost classifier training. After cessation of training the tests were performed with the aim of the estimation of effectiveness of recognition. Test session images were different from those ones which have been used for training of the classifier.

Results. The highest recall for appendicitis diagnostics was achieved after training of AdaBoost with MCLBT descriptors extracted from RGB images - 0,745, and in case for metastatic damages diagnostics - 0,902. Hence developed AdaBoost based CAD system achieved 74,4\% correct classification rate (accuracy) for appendicitisc and 89,3\% for metastatic images. The accuracy of HAAR features classifier was highest in case of metastatic foci identification and achieved 0,672 (RGB) - 0,723 (HSV) values.

Conclusions. Haar features based cascade classifier turned to be less effective when compared with AdaBoost classifier trained with MCLBT descriptors.
\end{abstract}

Key words: images analysis, machine learning, HAAR features, AdaBoost classifier, laparoscopic surgery. 


\title{
СРАВНИТЕЛЬНАЯ ЭФФЕКТИВНОСТЬ КЛАССИФИКАТОРОВ ИЗОБРАЖЕНИЙ В РАЗСПОЗНАВАНИИ ЗОН ИНТЕРЕСА ПРИ ЛАПАРОСКОПИЧЕСКИХ ВМЕШАТЕЛЬСТВАХ
}

\author{
Н. Р. Баязитов, Д. Н. Баязитов, А. Б. Бузиновский, \\ А. В. Ляшенко, Д. В. Новиков, Л. С. Годлевский \\ Одесский национальный медицинский университет
}

\begin{abstract}
В работе представлено сравнительные оценки эффективности систем автоматизированной компьютерной диагностики (АКД), разработанных на основе двух классификаторов - каскада дескрипторов Хaapa и AdaBoost, во время лапароскопической диагностики аппендицита и метастазов печени.

Для обучения применяли изображения, а также гамма-коррегированные и конвертированные в HSV шкалу RGB изображения, полученные при лапароскопической диагностике. Дескрипторы, которые использовали для обучения классификатора AdaBoost получали при помощи метода локального бинарного паттерна (ЛБП), который включал инорормационные показатели цвета («модифицированный цвет ЛБП» - МЦЛБП), а также показатели текстуры. После завершения обучения проводили тест оценки эфффективности диагностики, при котором использовали изображения, неприменяемые для обучения.

Наиболее высоким показатель полноты (recall) был при тестовой диагностике аппендицита с помощью классификатора AdaBoost в обучении применяли дескрипторы МЦЛБП, полученные при анализе RGB изображений — 0,745, а при диагностике метастазов печени - 0,902. Также корректность диагностики (accuracy) составила 74,4 \% при диагностике аппендицита и 89,3 \% при диагностике метастазов печени. Корректность диагностики при применении классификатора Хаара была наиболее высокой при диагностике метастазов печени и составила 0,672 при использовании RGB изображений и 0,723 - при обучении HSV изображениями.

Диагностика с применением классиорикатора Хаара менее эфффективна по сравнению с диагностикой, осуществляемой с применением классисикатора AdaBoost, обучение последнего проводили с применением дескрипторов МЦЛБП.
\end{abstract}

Ключевые слова: анализ изображений, машинное обучение, дескрипторы Хаара, классификатор AdaBoost, лапароскопическая хирургия. 
Вступ. Автоматизована комп'ютерна діагностика (АКД) / класифікація відео зображень є актуальною для вирішення проблем мінімальної інвазивної абдомінальної хірургії, а також ендоскопії [2, 3, 4, 8, 16]. Розроблено системи АКД для супроводження лапароскопічних інструментів [6, 9], ідентифікації зон патологічних змін [1, 5, 15, 13, 17].

При розробленні подібних систем визначається низка технічних труднощів. Зокрема, відсутність чітких відмінностей сусідніх елементів лапароскопічного зображення внаслідок високого шуму та нестабільного освітлення, а також висока варіабельність об’єктів дослідження, швидка зміна ракурсу їх візуалізації та відблиски світла ускладнюють діагностику [8]. Важливим є фактор превалювання відтінків червоного в палітрі кольору, що знижує інформативність зображень [8]. Одним із методів усунення зазначених перешкод при отриманні первинної інформації є застосування гама-корекції, що дозволяє встановити взаємовідношення числових характеристик окремих пікселей і визначити їхню яскравість [3].

3 метою аналізу потоку відео-зображень доцільним $є$ застосування каскадного класифікатора дескрипторів Хаара, що використовує швидкі алгоритми [16]. Застосування дескрипторів Хаара передбачає визначення загальних інформаційних характеристик певної сукупності пікселей, що здійснюється після розбиття первинного зображення на окремі регіони (вікна) $[14,16]$. Завдяки такому підходу виключається процес аналізу окремих пікселей і заощаджується час на проведення аналізу зображення, що дозволяє проводити аналіз відеозображення в реальному часі. Для кожного вікна визначається сума інтенсивностей сусідніх вікон і до уваги приймається різниця визначених характеристик. Отримана різниця дозволяє класифікувати зображення на основі порівняння із відповідними показниками зображень, використаних для навчання класифікатора, характеристики яких зберігаються в бібліотеці зображень.

Отже, критичним у використанні класифікатора Хаара $є$ коректне створення відповідної бібліотеки, де повинно знаходитись максимальне число варіантів патологічних змін у відповідній зоні (тканинаx). OpenCV бібліотека відповідає подібним вимогам [6]. Однак, її формування потребує значного періоду часу, що може складати місяці, коли для навчання використовують десятки тисяч зображень [16]. Подібна особливість — підвищення ефективності при зростанні числа зображень, що використовують при навчанні, ускладнює застосування класифікатора [6].

3 метою підвищення діагностичної ефективності класифікатора на основі дескрипторів Хаара доцільним було застосувати дескриптори кольору та текстури в процесі навчання. Такі характеристики текстури як медіана та шкала сірого разом із показником ентропії і контрасту можуть бути використані в якості ідентифікаторів фізіологічної норми досліджуваних тканин [7, 12], що склало одне із завдань цього дослідження. Крім класифікатора Хаара використовували класифікатор AdaBoost, в навчанні якого застосовували мінімальне число дескрипторів, що отримано при визначенні локального бінарного патерну (ЛБП). Класичний метод дослідження ЛБП використовує шкалу сірого та ігнорує інформацію інших кольорів. Також використовували модифікований метод ЛБП, що включав характеристики кольорів (модифікований метод кольорів ЛБП - МКЛБП) та дозволяв отримати дескриптори текстури $[10,11]$.

Мета роботи: проведення порівняльного оцінювання ефективності систем АКД на основі дескрипторів Хаара та каскадного класифікатора AdaBoost під час розпізнавання патологічних змін апендиксу (запалення) та метастазів печінки.

Матеріал і методи дослідження. До вимог, яких дотримувались щодо включення лапароскопічних відео відносились такі:

- задокументована калібровка цифрових камер, включаючи баланс білого кольору та конверсію шкали кольору в цифровий код;

- розташування об'єкту спостереження у фронтальній площині з відхиленням від перпендикуляру до неї на $15+5^{\circ}$ та відстанню до зони візуалізації від 3 до 5 см [1];

- зважаючи на відсутність рекомендацій щодо розміру зображення для його включення до бібліотеки OpenCV, а також попередній досвід авторів $[1,2]$ щодо розміру зразків зображень $24 \times 24$ пікселей при ендоскопічній діагностиці, включали зображення зони інтересу розмірами 60х60 пікселей. Для чого частоту відеокадрів модулювали за допомогою низькочастотного фільтра та розмір зображення штучно модифікували з 30х30 до 60х60 пікселей;

- проведення гама-корекції зображень із розрахунком гама-коефіцієнта;

- конверсія RGB шкали кольору в HSV шкалу; подібна конверсія виправдана тим, що дескриптори 
Хаара $є$ орієнтованими на оцінювання інтенсивності пікселей.

Навчання каскадного класифікатора Хаара проводили за допомогою RGB та HSV зображень, у той час як навчання класифікатора AdaBoost здійснювали за допомогою шаблонів МКЛБП. Результати класифікації зберігали в базі даних із можливістю відставленого в часі їх додаткового аналізу.
Всі лапароскопічні відеозаписи було отримано за допомогою відеокамери апертурою 5 мм протягом 2014-2019 pр. Камера обладнана аналоговим входом (PAL 475 горизонтальних ліній). Вхідний сигнал оцифровували при щільності пікселей 720x576, захоплення зображення здійснювалось за допомогою відеокарти «averMedia HD capture Studio 203» та виводилось на інтерфейс системи АКД (рис. 1).

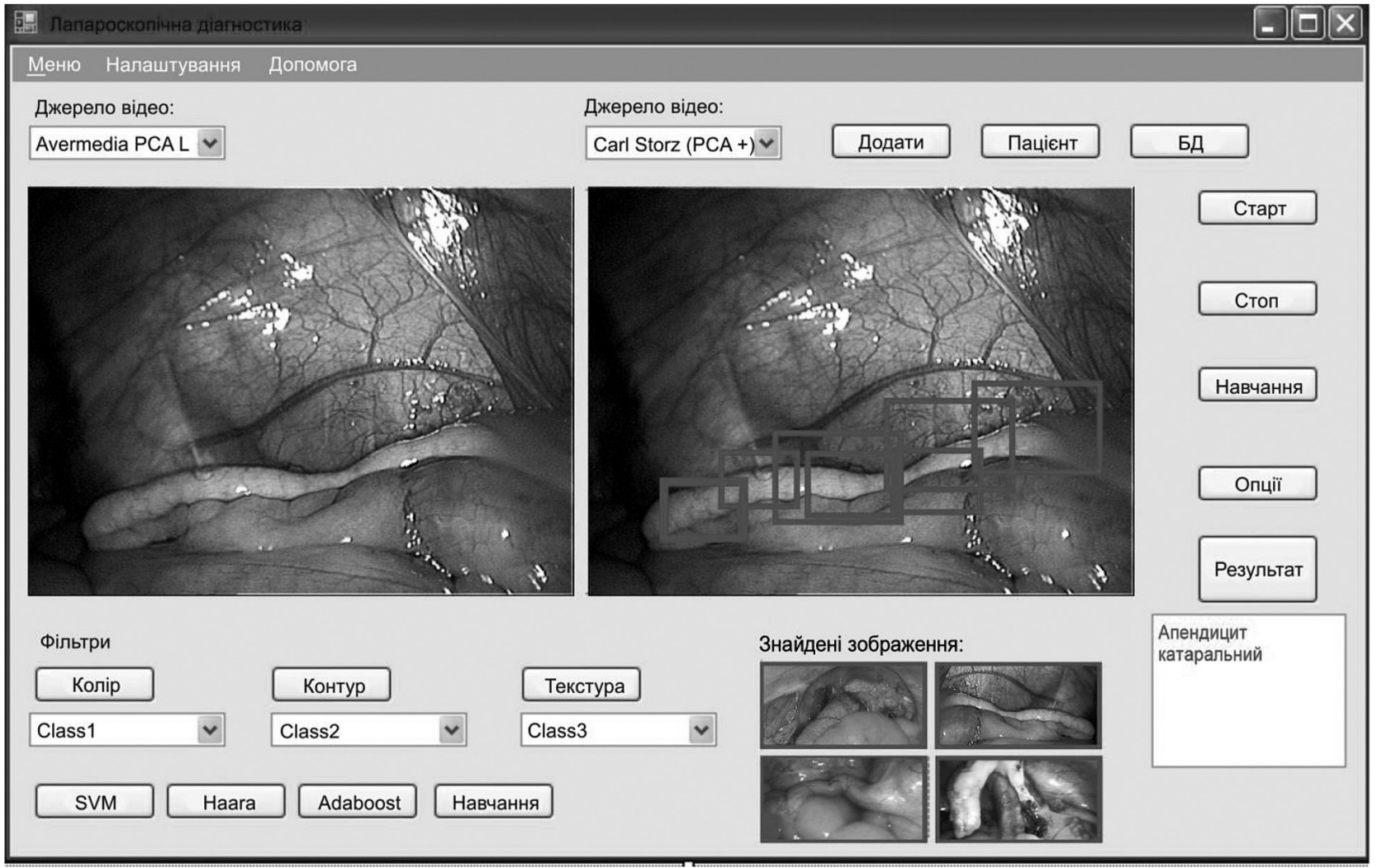

Рис. 1. Інтерфейс системи АКД під час діагностики апендициту

Отримання дескрипторів і навчання класифікаторів. За допомогою МКЛБП на RGB зображеннях розраховували показники локального бінарного патерну для R та G каналів нормалізованого RGB кольорового простору $[10,11]$. Подібний підхід дозволяв отримувати більш стабільні показники RGB - МКЛБП за умов різної інтенсивності освітлення. Характеристики текстури вираховували на Нuе — каналі HSV — MКЛБП, що були інваріантними до варіабельності освітлення та насиченості кольорів. Для розрахунку ЛБП використовували радіус 1,5, що включав 12 пікселей $[11,13]$. У результаті створювали певний патерн для кожного вектора шкали та визначали характерний вектор для шаблонів МКЛБП, що включав середні значення, ентропію, контраст, гомогенність та ексцес.

3 метою тренування класифікатора використовували 51 лапароскопічне відео пацієнтів із підтвердженим апендицитом та 39 відео пацієнтів із підтвердженими метастазами печінки. Також використовували «негативні» відео відповідних тканин без патологічних змін (40 відео для апендиксу та 40 - для печінки). Кожен відеоряд включав 25003000 фреймів, із яких у ручному режимі обирали зображення, що було використано для навчання.

Для навчання класифікаторів дотримувались таких вимог:

- розмір вікна окремого зображення складав 60x60 пікселів;

- число позитивних зображень (наявність патологічних змін) - n=1000 для кожного із діагностованих захворювань;

- число негативних зображень - $\mathrm{n}=500$.

Після закінчення навчання проводили тест на ефективність діагностики. Для його проведення 
використовували зображення, що відрізнялись від таких, які було використано на етапі навчання класифікатора. Тест виконували за допомогою 319 зображень запалення апендиксу та 217 зображень метастазів печінки. Також використовували 2035 зображень норми відповідних тканин.

Статистичні методи. Задля визначення ефективності діагностики класифікаторів розраховували показники точності, повноти, F-числа [3].

Точність визначали як відношення істинно позитивних розпізнавань до загального числа зображень: Точність = IП / (IП + ХП), де ІП - істино позитивні діагнози (розпізнавання); ХП - хибно позитивні діагнози.

Повноту розраховували як частку істинно позитивних розпізнавань до загального числа підтверджених діагнозів: Повнота = IП/ЗП, де ЗП - загальне число підтверджених діагнозів зображень, що було використано при контрольному тестуванні.

F-число розраховували як гармонійну середню величину точності та повноти: $\mathrm{F}=2 \mathrm{x}$ точність $\mathrm{x}$ повнота/точність + повнота.

Також розраховували показник акуратності (коректності) роботи класифікатора - відношення коректно класифікованих зображень до їх загального числа: Коректність (Асcuracy) = (IП + IН) / (IП + $\mathrm{IH}+\mathrm{XП} \mathrm{+} \mathrm{XН),} \mathrm{де} \mathrm{IH} \mathrm{-} \mathrm{число} \mathrm{істинно} \mathrm{негативних}$ діагнозів (розпізнавань), ХН - число хибно- негативних діагнозів.

Результати та їх обговорення. Отримані результати засвідчили, що автоматизована комп'ютерна діагностика апендициту була менш ефективною в порівнянні $з$ діагностикою метастазів печінки (рис. 2). Подібні відмінності реєструвались при навчання зображеннями як RGB, так i HSV форматів. Разом із тим, найбільш високим показник повноти був при діагностиці апендициту після навчання RGB - МКЛБП, який складав 0,902 i перевищував такий, що реєструвався при навчанні HSV - МКЛБП і який посідав за величиною друге місце - 0,851. Найбільш низьким показник повноти реєструвався при діагностиці апендициту за допомогою класифікатора на основі дескрипторів Хаара, навчання якого здійснювали RGB зображеннями $(0,456)$. Слід підкреслити, що під час діагностики апендициту, так само як і під час діагностики метастазів печінки класифікатори з навчанням із використанням МКЛБП результати були кращі порівняно з навчанням із застосуванням RGB та HSV зображень (рис. 2).
Навчання за допомогою МКЛБП характеристик визначених на основі аналізу RGB зображень забезпечувало збільшення числа істинно позитивних діагнозів порівняно до результатів діагностики за допомогою класифікатора Хаара: при діагностуванні апендициту в 1,7 разу і при діагностуванні метастазів печінки - в 1,5 разу. Паралельно відбувалось зменшення хибно негативних діагнозів - у 2,0 та в 3,4 разів відповідно. Менш виразне збільшення числа істинно позитивних діагнозів реєструвалось при застосуванні класифікаторів, що навчали за допомогою МКЛБП характеристик на основі аналізу HSV зображень: у 1,3 разу при діагностиці апендициту та в 1,2 разу при діагностиці метастазів печінки. Зменшення хибно-негативних діагнозів за цих умов склало 1,2 та 1,1 разу відповідно.

Отже, отримані результати свідчать про достатньо високу ефективність лапароскопічної діагностики захворювань, що $є$ причиною виникнення хронічного больового синдрому мискового походження, за допомогою систем АКД. Слід зазначити, що подібна ефективність раніше була досягнута при проведенні діагностики захворювань печінки [1]. Разом із тим, отримані результати вказують на порівняно меншу ефективність застосування каскадного класифікатора дескрипторів Хаара [1].

Однією з причин подібних відмінностей $є$ те, що класифікатор Хаара потребував більшого часу на аналіз потоку відеозображень, незважаючи на те, що конвертування зображень у HSV формат дещо покращувало результати діагностики. Значна варіабельність візуальних проявів патологічних змін тканин черевної порожнини (форма- контур, колір, текстура) разом із різними просторовими координатами розташування зон інтересу також $\epsilon$ факторами, що знижують діагностичну ефективність класифікатора Хаара [3, 13, 16].

Отримані результати засвідчили, що у випадку діагностування апендициту його ефективність була дещо меншою порівняно до діагностики метастазів печінки. Причому подібні відмінності зберігались за умов використання різних методів навчання. Також за різних умов навчання класифікатор Хаара був менш ефективним порівняно до AdaBoost класифікатора.

За результатами апробації розробленої діагностичної системи, при навчанні якої використовували модифіковані шаблони RGB i HSV зображень та мінімальні дескриптори МКЛБП, ефективність діагностики із застосуванням AdaBoost класифікатора 

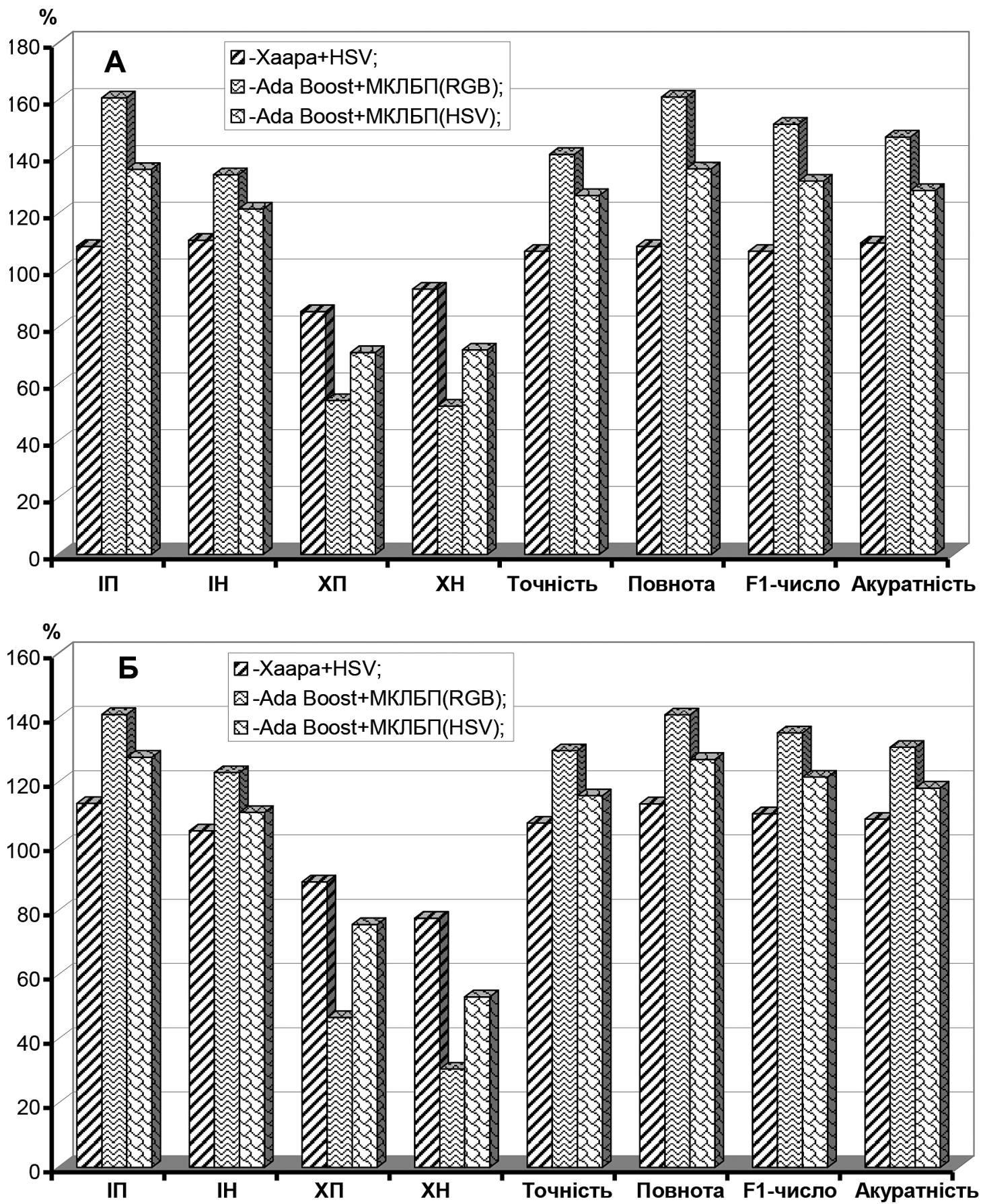

Рис. 2. Порівняльна ефективність каскадного класифікатора Хаара та Ada Boost класифікатора, в навчанні яких застосовували RGB та HSV зображення A — діагностика апендициту; Б — діагностика метастазів печінки. Позначки: по вісі абсцис — показники діагностичної ефективності класифікатора: IП — істинно позитивний, IH - істинно негативний, ХП — хибно позитивний, ХН — хибно негативний діагнози. МКЛБП - модифікований за кольором локальний бінарний патерн. За 100 \% прийнято показники ефективності класифікатора Хаapa, в навчанні якого застосовували RGB зображення

суттєво покращувалась. Так, число хибно негативних результатів за умов використання дескрипторів МКЛБП отриманих із RGB зображень при тестовому розпізнаванні апендициту зменшувалось у 2,0 разу, а при діагностуванні метастазів печінки в 3,4 разу в порівнянні до показників, отриманих при застосуванні класифікатора Хаара. Число істинно позитивних діагнозів у той же час зростало 
в 1,7 та в 1,5 разу відповідно. Подібні тенденції, однак менш виразні спостерігались при навчанні із застосуванні HSV типу зображень.

Також слід зазначити, що використання RGB зображень для навчання було більш ефективним, ніж застосування HSV зображень. Подібні відмінності узгоджуються із припущенням, що RGB шкала кольору більш адекватно відображує властивості м'яких тканин організму [7]. Незважаючи на перевагу дескрипторів Хаара, що полягає у відчутному скороченні часу розпізнавання зображень, а також запобіганні «перенавчання» класифікатора [2], використання МКЛБП - характеристик для навчання AdaBoost класифікатора $\epsilon$ більш ефективним для автоматичного розпізнавання лапароскопічних зображень. Також зберігається можливість того, що навчання каскадного класифікатора Хаара МКЛБП дескрипторами може сприяти підвищенню діагностичної ефективності так само як і навчання AdaBoost класифікатора за допомогою дескрипторів Хаара.

Доведено доцільності застосування МКЛБП дескрипторів для навчання AdaBoost класифікатора для розроблення методу автоматизованого

\section{Література.}

1. Інформаційно-технічна система для автоматизованої лапароскопічної діагностики / А. В. Ляшенко, Н. Р. Баязітов, Л. С. Годлевський та ін. // Радіоелектроніка, інфориматика, упрваління. - 2016.- Т. 4.C. 90-96.

2. The effectiveness of automatic laparoscopic diagnostics of liver pathology

using different methods of digital images classification / D. N. Bayazitov, N. V. Kresyun, A. B. Buzinovsky et al. // Патологія. — 2017. — Т. 14, № 2 (40). — С. 182-187.

3. Albisser Z. Computer-aided screening of capsule endoscopy videos / Z. Albisser // Master's Thesis, University of Oslo. - 2015.

4. Artificial Intelligence in Surgery: Promises and Perils / D. A. Hashimoto, G. Rosman, D. Rus, O. R. Meireles // Ann. Surg. - 2018. - Vol. 268 (1). — P. 70-76.

5. Surf: Speeded up robust features / H. Bay, T. Tuytelaars, L. Van Gool // Computer vision-ECCV. - 2006. Vol. 3951. - P. 404-417.

6. Bouguet J. Pyramidal implementation of the LucasKanade feature tracker: description of the algorithm, openCV documentation / J. Bouguet. — 2000. — Режим доступу: http://www.intel.com/research/mrl/reserach/ opencv.

7. Computer-aided diagnosis in hysteroscopic imaging / M. S. Neofytou, V. Tanos, I. Constantinou et al. // IEEE J Biomed Health Inform. — 2015.— Vol. 19 (3). P. 1129-1136. розпізнавання лапароскопічних зображень та лапаросокпічної діагностики.

Висновки. Розроблена система АКД лапароскопічних зображень на основі класифікатора AdaBoost дозволяє проводити ефективну діагностику апендициту та метастазів печінки з найвищим показником повноти діагностики при навчанні 3 використанням характеристик МКЛБП, отриманих при аналізі HSV зображень - до 0,85, для МКЛБП RGB - до 0,90.

МКЛБП характеристики, що були використані для навчання класифікатора AdaBoost спричиняли зростання точності, повноти, F1 - числа, а також акуратності автоматизованої діагностики апендициту та метастазів печінки.

Перспективи досліджень. Передбачається продовження навчання класифікаторів із застосуванням нових лапаросокпічних зображень і з розширенням числа нозологій, розширенням бібліотек OpenCV. Кращі версії системи АКД рекомендовано до застосування в клінічній практиці в режимі підтримки прийняття рішень хірургом.

8. Detection of unsafe action from laparoscopic cholecystectomy video / A. Lahane, Y. Yesha, M. Grasso et al. // Proc. 2nd ACM SIGHIT International Health Informatics Symposium. 2012. - P. 315-322.

9. Fatiev D. Faculty of Science and Technology Department of Computer Science Object tracking for improved telementoring and telestration / D. Fatiev // INF-3997 Master's Thesis in Telemedicine and E-health, The Arctic University of Norway. - 2015.

10. Ledoux A. Color local binary patterns: compact descriptors for texture classification / A. Ledoux, O. Losson, L. Macaire // Journal of Electronic Imaging, Society of Photo-optical Instrumentation Engineers. 2016. — Vol. 25 (6). — P. 061404.

11. Ojala T. Multiresolution gray-scale and rotation invariant texture classification with local binary patterns / T. Ojala, M. Pietikainen, T. Maenpaa // IEEE Transactions on Pattern Analysis and Machine Intelligence. — 2002. — Vol. 4 (7). - P. 971-987.

12. Learning laparoscopic video shot classification for gynecological surgery / S. Petscharnig, K. Schöffmann // Multimed. Tools Appl. — 2018. — Vol. 77. — P. 8061-8079.

13. Polyp detection and radius measurement in small intestine using video capsule endoscopy / M. Zhou, G. Bao, Y. Geng // Proc 7th International Conference on Biomedical Engineering and Informatics (BMEI). 2014.- P. 237-241. 
14. Segmentation of laparoscopic images: Integrating graphbased segmentation and multistage region merging / Y. Shu, G. A. Bilodeau, F. Cheriet // Proc 2nd Canadian Conference on Computer and Robot Vision (CRV'05). $-2005$.

15. SurgAI: deep learning for computerized laparoscopic image understanding in gynaecology / S. Madad Zadeh, T. Francois, L. Calvet et al. // Surg. Endosc. - 2020. - Режим доступу: https://link.springer.com/article/1 0.1007\%2Fs00464-019-07330-8.

16. Rapid object detection using a boosted cascade of simple features / P. Viola, M. Jone s// Proc IEEE Computer Society Conference on Computer Vision and Pattern Recognition. - 2001. - Vol. 1. - P. 511-518.

17. 3D shape tracking of minimally invasive instruments using optical frequency domain reflectometry / F. Parent, K. K. Mandal, S. Loranger et al. — San Diego: SPIE Medical Imaging, 2016. — 9786 p.

\section{References.}

1. Lyashenko, A. V., Bayazitov, N. R., Godlevsky, L. S. et al. (2016). Informational-technical system for the automatized laparoscopic diagnostics. Radio Electronics, Computer Science, Control, 4, 90-6. [In Ukrainian].

2. Bayazitov, D. N., Kresyun, N. V., Buzinovsky, A. B. et al. (2017). The effectiveness of automatic laparoscopic diagnostics of liver pathology using different methods of digital images classification. Patologiya (Pathology), 14, № 2 (40), 182-7.

3. Albisser Z. (2015). Computer-aided screening of capsule endoscopy videos. Master's Thesis, University of Oslo.

4. Hashimoto, D. A., Rosman, G., Rus, D., Meireles, O. R. (2018). Artificial Intelligence in Surgery: Promises and Perils. Ann.Surg., 268 (1), 70-6. doi: 10.1097/ SLA.0000000000002693.

5. Bay, H., Tuytelaars, T., Van Gool, L. (2006). Surf: Speeded up robust features. Computer vision-ECCV, 3951, 404-17.

6. Bouguet J. (2000). Pyramidal implementation of the Lucas-Kanade feature tracker: description of the algorithm, openCV documentation. Available on: http:// www.intel.com/research/mrl/reserach/opencv.

7. Neofytou, M. S., Tanos, V., Constantinou, I. et al. (2015). Computer-aided diagnosis in hysteroscopic imaging. IEEE J Biomed Health Inform., 19 (3), 1129-36.
8. Lahane, a., Yesha, Y., Grasso, M. et al. (2012). Detection of unsafe action from laparoscopic cholecystectomy video. Proc. 2nd ACM SIGHIT International Health Informatics Symposium, 315-22.

9. Fatiev D. (2015). Faculty of Science and Technology Department of Computer Science Object tracking for improved telementoring and telestration. INF-3997 Master's Thesis in Telemedicine and E-health, The Arctic University of Norway.

10. Ledoux, A., Losson, O., Macaire, L. (2016). Color local binary patterns: compact descriptors for texture classification. Journal of Electronic Imaging, Society of Photo-optical Instrumentation Engineers, 25 (6), 061404. Available on: http://dx.doi.org/10.1117/1. JEI.25.6.061404.

11. Ojala, T., Pietikainen, M., Maenpaa, T. (2002). Multiresolution gray-scale and rotation invariant texture classification with local binary patterns. IEEE Transactions on Pattern Analysis and Machine Intelligence, 4 (7), 971-87.

12. Petscharnig, S., Schöffmann, K. (2018). Learning laparoscopic video shot classification for gynecological surgery. Multimed. Tools Appl., 77, 8061-79.

13. Zhou, M., Bao, G., Geng, Y. (2014). Polyp detection and radius measurement in small intestine using video capsule endoscopy. Proc 7th International Conference on Biomedical Engineering and Informatics (BMEI), 237-41.

14. Shu, Y., Bilodeau, G. A., Cheriet, F. (2005). Segmentation of laparoscopic images: Integrating graph-based segmentation and multistage region merging. Proc 2nd Canadian Conference on Computer and Robot Vision (CRV'05), doi: 10.1109/ CRV. 2005.74.

15. Madad Zadeh, S., Francois, T., Calvet, L. et al. (2020). SurgAI: deep learning for computerized laparoscopic image understanding in gynaecology. Surg. Endosc. Available on: https://doi.org/10.1007/s00464-01907330-8.

16. Viola, P., Jones M. (2001). Rapid object detection using a boosted cascade of simple features. Proc IEEE Computer Society Conference on Computer Vision and Pattern Recognition., 1, 511-518.

17. Parent, F., Mandal, K. K., Loranger, S. et al. (2016). 3D shape tracking of minimally invasive instruments using optical frequency domain reflectometry. Proc of SPIE, 9786. doi: 10.1117/12.2214998. 